OPEN ACCESS

Edited by:

Zdena Palkova,

Charles University, Czechia

Reviewed by:

Nehal Mohammed Eldeeb,

City of Scientific Research

and Technological Applications, Egypt

Sónia Silva

University of Minho, Portugal

Célia F. Rodrigues,

University of Porto, Portugal

Yijie Dong,

Chinese Academy of Agricultural

Sciences (CAAS), China

Justyna Karkowska-Kuleta,

Jagiellonian University, Poland

*Correspondence:

Susumu Kajiwara

skajiwar@bio.titech.ac.jp

Specialty section:

This article was submitted to

Cell Death and Survival,

a section of the journal

Frontiers in Cell and Developmental

Biology

Received: 16 September 2020

Accepted: 22 January 2021

Published: 12 February 2021

Citation:

Chen X, Iwatani S, Kitamoto T,

Chibana H and Kajiwara S (2021) The

Lack of SNARE Protein Homolog

Syn8 Influences Biofilm Formation

of Candida glabrata.

Front. Cell Dev. Biol. 9:607188.

doi: 10.3389/fcell.2021.607188

\section{The Lack of SNARE Protein Homolog Syn8 Influences Biofilm Formation of Candida glabrata}

\author{
Xinyue Chen ${ }^{1}$, Shun Iwatani ${ }^{1}$, Toshitaka Kitamoto ${ }^{2}$, Hiroji Chibana ${ }^{3}$ and \\ Susumu Kajiwara ${ }^{1 *}$ \\ 1 School of Life Sciences and Technology, Tokyo Institute of Technology, Yokohama, Japan, ${ }^{2}$ School of Materials \\ and Chemical Technology, Tokyo Institute of Technology, Yokohama, Japan, ${ }^{3}$ Medical Mycology Research Center, Chiba \\ University, Chiba, Japan
}

Biofilm formation of Candida species is considered to be a pathogenic factor of host infection. Since biofilm formation of Candida glabrata has not been as well studied as that of Candida albicans, we performed genetic screening of C. glabrata, and three candidate genes associated with biofilm formation were identified. Candida glabrata SYN8 (CAGLOH06325g) was selected as the most induced gene in biofilm cells for further research. Our results indicated that the syn8 $\Delta$ mutant was defective not only in biofilm metabolic activity but also in biofilm morphological structure and biomass. Deletion of SYN8 seemed to have no effect on extracellular matrix production, but it led to a notable decrease in adhesion ability during biofilm formation, which may be linked to the repression of two adhesin genes, EPA10 and EPA22. Furthermore, hypersensitivity to hygromycin $B$ and various ions in addition to the abnormal vacuolar morphology in the syn8 $\Delta$ mutant suggested that active vacuolar function is required for biofilm formation of $C$. glabrata. These findings enhance our understanding of biofilm formation in this fungus and provide information for the development of future clinical treatments.

Keywords: Candida glabrata, biofilm formation, genetic screening, SNARE protein, vacuole

\section{INTRODUCTION}

Candida glabrata, identified as a non-albicans Candida (NAC) species, is one of the common causes of systemic candidiasis and shows resistance to most azole drugs (Rodrigues et al., 2014; Pristov and Ghannoum, 2019). However, studies on the mechanisms of virulence in C. glabrata are far fewer than those in C. albicans. The biofilm of Candida species is known to be a pathogenic factor in human infections and difficult to eradicate in healthcare settings (Douglas, 2003; Eix and Nett, 2020). In C. glabrata, the biofilm is composed of only yeast-shaped cell clusters packed in a multilayer, which is quite different from biofilms of $C$. albicans with their elongated filamentous forms (Brunke and Hube, 2013). Because C. glabrata lacks filamentous growth, it is important to investigate its own distinctive biofilm pathogenicity.

Biofilm formation is a complex process that includes adhesion, colonization, extracellular matrix production, biofilm maturation, and dispersal (Ramage et al., 2009). The first step is Candida cell adhesion to the surfaces of host cells and biomaterials such as silicone. Therefore, many previous studies have investigated the roles of adhesins at the cell surface in biofilm formation. The EPA (epithelial adhesin) gene family is a major group of adhesins in C. glabrata. Because the 
C. glabrata haploid genome is more closely related to Saccharomyces cerevisiae than C. albicans, this large EPA family is similar to the FLO gene family of $S$. cerevisiae, which encodes lectins for flocculation (de Groot et al., 2008). In particular, EPA3 and EPA6 have been indicated as encoding the main adhesins involved in biofilm formation of C. glabrata (Iraqui et al., 2005; Cavalheiro et al., 2018). Furthermore, EPA6 expression is positively regulated by a Yak1p kinase that acts through a subtelomeric silencing pathway and by the chromatin remodeling Swi/Snf complex, whereas it is negatively regulated by the transcription factor Cst6p (Iraqui et al., 2005; Riera et al., 2012). The Swi/Snf nucleosome-remodeling complex interacts with the nucleosomes via the Snf2p and Snf6p components. SNF2 and SNF6 gene disruption mutants also exhibit poor ability to form biofilms (Riera et al., 2012). Pgs1p is a phosphatidylglycerol phosphate synthase, and it has been reported that deletion of the PGS1 gene results in increased cell surface hydrophobicity and decreased biofilm formation of C. glabrata (Bat'ová et al., 2009). In addition to proteins that act on cell wall synthesis related to the adhesion step during biofilm formation, some recent studies have reported that the multidrug resistance transporters Pdr16p and Tpo1_2p contribute to azole resistance and are related to biofilm formation (Culakova et al., 2013; Santos et al., 2017). More recently, Dtr1p, Qdr2p, and Tpo4p drug:H + antiporters were found to be associated with biofilm formation of C. glabrata (Widiasih Widiyanto et al., 2019; Santos et al., 2020). Thus, it seems like a broad range of proteins, which are valuable to study, affect the process of biofilm formation of C. glabrata.

Comprehensive screening of biofilm-related genes in fungi was commonly used the collections of gene mutants (Iraqui et al., 2005; Vandenbosch et al., 2013), and the genetic expression analysis comparing the biofilm form with planktonic cells (García-Sánchez et al., 2004; Nobile et al., 2012). However, these previous studies have mostly used $C$. albicans and $S$. cerevisiae rather than C. glabrata. The aim of this study was to identify new genes involved in biofilm formation of C. glabrata. Through a comprehensive screening of 101 C. glabrata mutants, three gene mutants exhibited less than $70 \%$ of the metabolic activity compared with the wild type strain. Our study focused on one of the new genes, SYN8 (CAGL0H06325g), which encodes a SNARE (soluble N-ethylmaleimide-sensitive factor attachment protein receptor) protein in C. glabrata. Although there have been many studies on the roles of cell wall proteins in the biofilm formation of C. glabrata, the relationship between biofilm formation and SNARE proteins is unclear. This is the first study to investigate the role of the SNARE Syn8p in C. glabrata, and we demonstrated that this gene is involved in normal vacuolar function. In addition, our results suggested that SYN8 influences the biofilm formation of C. glabrata.

\section{MATERIALS AND METHODS}

\section{Strains and Media}

The C. glabrata strains used in this study are listed in Table 1 and Supplementary Table 1. All yeast strains were typically grown in YPD medium (1\% Bacto yeast extract, 2\%
TABLE 1 | Strain list.

\begin{tabular}{lllc}
\hline Strain & Parent & Genotype & References \\
\hline CBS138 & & Wild type strain & Ueno et al., 2007, 2011 \\
2000H & 2001U & his3:ScURA3 ura3 & Ueno et al., 2007, 2011 \\
KUE100 & 2000H & his3 yku80:SAT1 flipper & Ueno et al., 2007, 2011 \\
syn8 & KUE100 & his3 yku80:SAT1 syn8:CgHIS3 & This study \\
SYN8 & syn8 & his3 yku80:SAT1 SYN8:CgHIS3 & This study \\
\hline
\end{tabular}

Bacto-peptone and 2\% glucose) or CSM medium (pH 5.8) (0.67\% Bacto Yeast Nitrogen base without amino acids, $0.079 \%$ CSM complete supplement mixture, and $2 \%$ glucose) at $37^{\circ} \mathrm{C}$. Solid media were supplemented with $2 \%$ agar. Chemicals used in these experiments were obtained from Nacalai Tesque, Difco Laboratories, and Wako.

\section{Plasmid Construction}

The C. glabrata mutant library was constructed using the method described previously (Ueno et al., 2007), and the information of gene sequence was provided by Candida Genome Database (Koszul et al., 2003). The gene deletion was carried out in the parental strain KUE100. The target gene was replaced by a DNA replacement cassette including the $\mathrm{CgHIS} 3$ gene through homologous recombination. The pHIS906 plasmid including $\mathrm{CgHIS3}$ was used as a template (Figure 1A). Recombination loci and gene deletion were verified by PCR.

To construct the SYN8 reintegrated strain from the syn $8 \Delta$ mutant, C. glabrata wild type genomic DNA was extracted from the CBS138 strain and used as the template to amplify the SYN8 ORF with a $500 \mathrm{bp}$ promoter and $200 \mathrm{bp}$ terminator. The primers pSyn8compF and pSyn8compR were designed to amplify the SYN8 (1.5 kb) fragments. Next, the plasmid pZeoi_comp606 and the amplified $1.5 \mathrm{~kb}$ fragment were digested, respectively, and then ligated together to construct pZeoi_SYN8 (Figure 1B). The sequence of the SYN8 gene was confirmed by a DNA sequencer (Open Research Facilities for Life Science and Technology, Tokyo Institute of Technology). The primers pChr606F1 and pChr606R1 were used to amplify the cassette from pZeoi_SYN8, and the purified DNA product was transformed into the noncoding region on chromosome $\mathrm{F}$ position 605,901-606,015 of the mutant syn $8 \Delta$. Successful integration at the right position on the transformant genome was confirmed by the primers pZeoORFcheckF1 and pchr606check. All primer sequences used in this experiment are shown in Table 2 and designed by the software Primer 3.

\section{Transformation of C. glabrata}

After constructing the integration cassettes, the cassettes were introduced into the C. glabrata syn $8 \Delta$ strain based on a previous method with slight modification (Ueno et al., 2011). The strain colonies were incubated in YPD liquid medium and cultured overnight with shaking at $37^{\circ} \mathrm{C}$. The cultured cells were resuspended in $10 \mathrm{~mL}$ fresh YPD medium and grown from an $\mathrm{OD}_{600}$ of $0.4-1.0$ at $37^{\circ} \mathrm{C}$. These cells were resuspended in $10 \mathrm{~mL}$ of $0.15 \mathrm{M}$ lithium acetate dissolved in TE buffer (LiOAc/TE) and shaken lightly for $1 \mathrm{~h}$ at $37^{\circ} \mathrm{C}$. Then the cells were again 
A

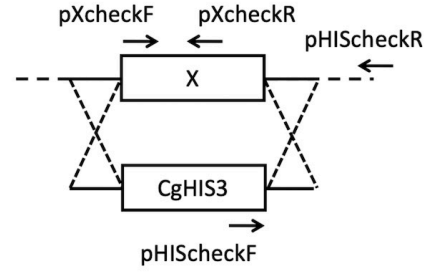

B

Chromosome $\mathrm{F}$ non-coding region

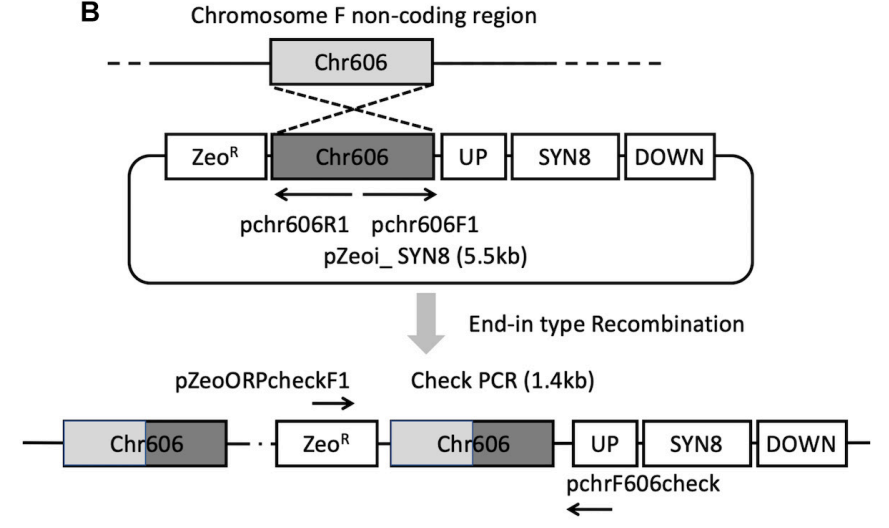

FIGURE 1 | Strategies for gene deletion (A) and SYN8 reintegration (B).

harvested and resuspended in $400 \mu \mathrm{L}$ of $0.15 \mathrm{M}$ LiOAc. Sixty microliters of the cell suspension were supplemented with $20 \mu \mathrm{g}$ single-stranded carrier DNA and 5-10 $\mu$ g integration cassette DNA solution and mixed gently in a new $1.5 \mathrm{~mL}$ tube. The cell suspension was incubated at $37^{\circ} \mathrm{C}$ with rotation for $37 \mathrm{~min}$ and then mixed completely with $120 \mu \mathrm{L}$ of $52.5 \%$ polyethylene glycol $4000,0.15 \mathrm{M} \mathrm{LiOAc}$ by pipetting. The cells were incubated again for $45 \mathrm{~min}$ at $37^{\circ} \mathrm{C}$ and heat-shocked at $42^{\circ} \mathrm{C}$ for $15 \mathrm{~min}$. Then, the cells were harvested and incubated in $1 \mathrm{~mL}$ of fresh YPD liquid medium for 12 or $24 \mathrm{~h}$ at $37^{\circ} \mathrm{C}$ with shaking for recovery. After that, cells were spread on YPD plates containing zeocin (50-200 $\mu \mathrm{g} / \mathrm{mL}$ ) and incubated at $37^{\circ} \mathrm{C}$ for $1-2$ days.

\section{Biofilm Formation and Plate Siliconization}

C. glabrata biofilms were formed according to an in vitro method using a 96-well flat-bottom polystyrene plate (IWAKI, Japan) (Widiasih Widiyanto et al., 2019). Yeast cells were cultured overnight at $37^{\circ} \mathrm{C}$. Cells were harvested by centrifugation and washed twice in $100 \mu \mathrm{L}$ sterile phosphate-buffered saline buffer

TABLE 2 | Primers for SYN8 deletion and reintegration.

\begin{tabular}{ll}
\hline Primers & Primer sequence $\left(\mathbf{5}^{\prime} \rightarrow \mathbf{3}^{\prime} \mathbf{)}\right.$ \\
\hline pSyn8F & THGCGTTGAACCCCGGGATTAAGGATGGATTACTGTAT \\
pSyn8R & $\begin{array}{l}\text { GAAATATTGAATGGTAGTATCTGTAATAATGGTTAATCTCAT } \\
\text { CAAACTGAGATGCTCATCGTGAGGCTGG }\end{array}$ \\
pHIScheckF & CAGCCATTGTATGCCACTGTATGA \\
pHIScheckR & CAGCTTATCTCAGAAACCAG \\
pSyn8checkF & GGATCTGAAGGTTCATATGAGCTTGA \\
pSyn8checkR & GAAAAGTCATTGGGGCTGATGCA \\
pSyn8compF & AATCTAGAATCTATCCTCCATGGGCTCCTT \\
pSyn8compR & AATCTAGATCTGTGATGAGCCGAATCAGAATC \\
pChr606 F1 & AAGAATGCCAACCAAGGATTCACAATAATCCGAAGC \\
pChr606 R1 & TTAGGCAAAGCATTGTAAACCATTACAAGCACTC \\
pZeoORFcheckF1 & AAGTTGACCAGTGCCGTTCCGGTG \\
pchr606check & CTAATGGGGATATAGAAAGATAGGG
\end{tabular}

(PBS, $137 \mathrm{mmol} / \mathrm{L} \mathrm{NaCl}, 2.7 \mathrm{mmol} / \mathrm{L} \mathrm{KCl}, 10 \mathrm{mmol} / \mathrm{L} \mathrm{Na}_{2} \mathrm{HPO}_{4}$, $2 \mathrm{mmol} / \mathrm{L} \mathrm{KH}_{2} \mathrm{PO}_{4}, \mathrm{pH}$ 7.2). Then cells were resuspended in fresh medium and standardized to a concentration of $10^{7}$ cells $/ \mathrm{mL}$. Each well of the plate was filled with a $100 \mu \mathrm{L}$ aliquot of cell suspension, and the plates were incubated at $37^{\circ} \mathrm{C}$ for $1.5 \mathrm{~h}$ to allow the cells to adhere to the surfaces of the wells. Following the adhesion phase, the cell suspensions were removed, and the wells were washed with PBS buffer to remove non-adherent cells. Fresh medium $(100 \mu \mathrm{L})$ was added to each well, and then the plate was incubated at $37^{\circ} \mathrm{C}$ for $24 \mathrm{~h}$. The siliconized plates were also used to compare the influence of the silicone material on biofilm formation. Three hundred microliters of Sigmacote (Sigma-Aldrich, United States) were added into the well of a plate and distributed over the well according to the product information. Because the reaction was almost instantaneous, the rest of the Sigmacote was quickly removed. After all of the wells of one plate were treated, the whole plate was dried in a hood with UV sterilization. The silicone is covalently bound to the well.

\section{XTT Reduction Assay}

2,3-Bis(2-methoxy-4-nitro-5-sulfophenyl)-5-[(phenylamino) carbonyl]-2H-tetrazolium-5-carboxanilide (XTT) reduction assay was used to measure the metabolic activity of biofilms of C. glabrata as described previously (Chen et al., 2017). Briefly, after washing the biofilm with $100 \mu \mathrm{L}$ PBS buffer, a $100 \mu \mathrm{L}$ aliquot of XTT-menadione was added into each well. The plate was then incubated for $2 \mathrm{~h}$ at $37^{\circ} \mathrm{C}$, and the colorimetric change was measured at $490 \mathrm{~nm}$ by a microtiter plate reader (VarioskanLUX, ThermoFisher, Japan). Negative controls were the unseeded wells. The final result for each strain was confirmed at least three independent times.

\section{Observation of Biofilms by SEM}

To observe the microstructures of C. glabrata biofilms, sterile 3-mm cubic silicone sponges (AS ONE Corp., Japan) were prepared and put into a 96-well plate before cell cultivation. Aliquots $(200 \mu \mathrm{L})$ of precultured cell suspensions were added in the plate, and the biofilm was allowed to form subsequently on the silicone sponges. These samples were treated as described before 
(Chen et al., 2017). The biofilm microstructures of C. glabrata were observed by a desktop scanning electron microscope, Phenom ${ }^{\mathrm{TM}}$-Pro-X (Phenom-World, Netherlands).

\section{Biofilm Dry Weight and Matrix Analysis}

Biofilms for matrix collection were formed in 12-well polystyrene microtiter plates (IWAKI, Japan). Three-milliliter aliquots of cell suspensions that were diluted to $1 \times 10^{7}$ cells $/ \mathrm{mL}$ were filled in each well. After incubation at $37^{\circ} \mathrm{C}$ for $24 \mathrm{~h}$, the matrix of each biofilm was collected using a previously described method with slight modification (Silva et al., 2009; Taff et al., 2012). Biofilms were scraped from the wells and resuspended with $5 \mathrm{~mL}$ distilled water in tubes. The tubes were sonicated for $10 \mathrm{~min}$, vortexed vigorously for $5 \mathrm{~min}$, and centrifuged at $5,000 \times g$ for $10 \mathrm{~min}$ at $4^{\circ} \mathrm{C}$. The supernatant was transferred into new tubes to separate cell pellets from soluble matrix material and stored at $-20^{\circ} \mathrm{C}$. To measure the biofilm dry weight, the remaining pellets were dried at $60^{\circ} \mathrm{C}$ until a constant weight. The supernatant samples were used to determine the contents of proteins and total carbohydrates. The protein content of each biofilm matrix was measured by using Protein Assay CBB Solution $(5 \times)$ (Nacalai Tesque, Japan). Bovine serum albumin (BSA) $(2.5-25 \mu \mathrm{g} / \mathrm{mL})$ was used to make the standard curve for the protein test. The absorbance was read at $595 \mathrm{~nm}$. The total carbohydrate content of each biofilm matrix was detected based on the phenol-sulfuric acid method (Dubois et al., 1956). Briefly, $1 \mathrm{~mL}$ sample was mixed well with $250 \mu \mathrm{L} 80 \%$ phenol (wt/wt in $\mathrm{H}_{2} \mathrm{O}$ ) and added rapidly with $2.5 \mathrm{~mL} \mathrm{H}_{2} \mathrm{SO}_{4}$. Finally, after the tubes cooled down to room temperature, the samples were mixed well and the absorbance was read at $490 \mathrm{~nm}$. Glucose (5-500 $\mu \mathrm{g} / \mathrm{mL}$ ) was used to make the standard curve for the total carbohydrate test.

\section{Real-Time PCR}

The planktonic cells were cultured in CSM medium at $37^{\circ} \mathrm{C}$. The culture was diluted to an $\mathrm{OD}_{600}$ of 0.2 in $50 \mathrm{~mL}$ fresh CSM medium before being grown to $\mathrm{OD}_{600}$ of $1 \sim 2$. The biofilm cells were induced to form in 12-well plates for $24 \mathrm{~h}$ as described above. Total RNA was extracted from unicellular cells and biofilm cells using the glass bead lysis method. These RNAs were used as templates to synthesize first strand cDNA using the ReverTra Ace qPCR RT Master Mix with gDNA Remover kit (TOYOBO, Japan). Real-time PCR was performed by using the THUNDERBIRD SYBR qPCR Mix kit (TOYOBO, Japan) and gene expression levels were determined by using $\Delta \Delta \mathrm{C}_{\mathrm{t}}$ method. The gene expression values were normalized by comparison to the expression of a housekeeping gene, CgACT1 (Pfaffl, 2001). All the primers for real-time PCR reactions were listed in Table 3.

\section{Susceptibility to Drugs and lons}

Cells were cultured in $5 \mathrm{~mL}$ YPD medium overnight at $37^{\circ} \mathrm{C}$. The overnight cultures were then diluted to an $\mathrm{OD}_{600}$ of 0.1 , which was used as a starting point for 10-fold serial dilutions. Three microliters of each serial dilution were spotted onto YPD plates containing drugs and ions (Banuelos et al., 2010; Palanisamy et al., 2010). The final concentrations of each drug were $0.01 \%$
TABLE 3 | Primers for RT-qPCR.

\begin{tabular}{ll}
\hline Primers & Primer sequence $\left(\mathbf{5}^{\prime} \boldsymbol{\rightarrow} \mathbf{3}^{\prime} \mathbf{)}\right.$ \\
\hline ACT1F & CCTACGAATTGCCAGATGGT \\
ACT1R & ACAGATGGGTGGAACAAAGC \\
SYN8F & CATCAGCCCCAATGACTाT \\
SYN8R & TGCCAAGGAATCAAGATGTG \\
EPA1F & GATTGCTGCAGAAGGGATTC \\
EPA1R & CTGTTTTGAGCCCCAGATG \\
EPA6F & ATCAGGATCGAATCCATGTTG \\
EPA6R & ACAGCGAAGTACACCCCATT \\
EPA10F & GGGACAGACCACGATCACTT \\
EPA10R & AACCACCACCAGGAACCATA \\
EPA22F & ACTTGGCGAGTACGTTGCTT \\
EPA22R & TGATCCGGAACGGAATAGAG \\
\hline
\end{tabular}

SDS, $70 \mu \mathrm{g} / \mathrm{mL}$ hygromycin $\mathrm{B}, 80 \mu \mathrm{g} / \mathrm{mL}$ calcofluor white, and $100 \mu \mathrm{g} / \mathrm{mL}$ Congo red. Concentrations of ions were as follows: $4 \mathrm{mM} \mathrm{ZnCl}_{2}, 10 \mathrm{mM} \mathrm{MnCl}_{2}, 1 \mathrm{M} \mathrm{NaCl}, 1 \mathrm{M} \mathrm{KCl}$. The plates were then incubated at $37^{\circ} \mathrm{C}$ for $24-60 \mathrm{~h}$. Chemicals used in these experiments were obtained from Nacalai Tesque, Difco Laboratories, Wako, and Funakoshi in Japan.

\section{Antifungal Susceptibility of Unicellular Cells by Broth Dilution}

Minimum inhibitory concentration (MIC) assays were prepared based on EUCAST guidelines (Rodríguez-Tudela et al., 2003). Briefly, cells were cultured overnight in CSM medium, washed twice by PBS buffer, and resuspended in RPMI medium to a concentration of $10^{4}$ cells $/ \mathrm{mL}$. Volumes of $100 \mu \mathrm{L}$ of cells including hygromycin B were filled in 96-well microtiter plate wells. The concentration range of the 2 -fold drug dilutions was from 7.8125 to $500 \mu \mathrm{g} / \mathrm{mL}$. The plates were incubated at $37^{\circ} \mathrm{C}$ for $24 \mathrm{~h}$ and then read by a microtiter plate reader at $530 \mathrm{~nm}$.

\section{Antifungal Susceptibility of Biofilm Cells by XTT Assay}

Sessile Minimum Inhibitory Concentration (SMIC) of biofilm cells was tested as previously published (Ramage et al., 2001). Biofilms were formed as described above. After $24 \mathrm{~h}$, the suspension was discarded, and wells were washed twice by $100 \mu \mathrm{L}$ PBS buffer. In order to avoid disruptions of biofilms, different concentrations of 2-fold antifungal agent dilutions were prepared separately in medium $(62.5-1,000 \mu \mathrm{g} / \mathrm{mL})$, and $100 \mu \mathrm{L}$ amounts of each antifungal concentration were added into the wells. Controls were prepared with biofilm wells that were untreated with drugs or unseeded wells with medium only. The plates were incubated at $37^{\circ} \mathrm{C}$ for $24 \mathrm{~h}$ again. After $24 \mathrm{~h}$, the plates were carefully washed with $100 \mu \mathrm{L}$ PBS. To determine XTT activity, $100 \mu \mathrm{L}$ of a $1 \mathrm{mg} / \mathrm{mL}$ solution of XTT-menadione was put into each well and the plates incubated for $2 \mathrm{~h}$. Absorbance at $492 \mathrm{~nm}$ was measured by a microtiter plate reader. The lowest concentrations associated with a 50 or $90 \%$ reduction in absorption compared with the untreated biofilm wells were reported as the $\mathrm{MIC}_{50}$ or $\mathrm{MIC}_{90}$. 


\section{Visualization of Vacuolar Morphology}

To visualize the cell vacuolar morphology, the fluorescent dye FM4-64 [N-(3-triethylammoniumpropyl)-4-(6-(4(diethylamino) phenyl) hexatrienyl) pyridinium dibromide] (SynaptoRed C2) (Wako, Japan) was used to stain vacuolar membranes (Vida and Emr, 1995). The cells were cultured for $16 \mathrm{~h}$ overnight and inoculated into fresh medium for more $6 \mathrm{~h}$ until $\log$ phase. Then, cells were resuspended to $2-4 \mathrm{OD}_{600}$ in fresh medium with $40 \mu \mathrm{M}$ FM4-64 and incubated for $15 \mathrm{~min}$ at $37^{\circ} \mathrm{C}$. After this preliminary labeling step, the cells were harvested at room temperature and resuspended to $1 \mathrm{OD}_{600}$ in fresh medium and incubated for $45 \mathrm{~min}$ at $37^{\circ} \mathrm{C}$. After this, the cells were resuspended to $2-4 \mathrm{OD}_{600}$ and observed by confocal laser scanning microscopy (CLSM) LSM780 (ZEISS, Japan). Red fluorescence filters (excitation filter, $533-588 \mathrm{~nm}$; barrier, $608-683 \mathrm{~nm}$ ) were used to visualize vacuolar membranes stained with FM4-64.

\section{RESULTS}

A comprehensive screening of C. glabrata mutants was performed by using our C. glabrata mutant library. The null mutants of 101 genes that encode proteins including signal peptides or transmembrane domains were selected and screened for their biofilm formation abilities. The biofilm formation abilities of 101 mutants were compared with that of the reference strain (Supplementary Figure 1 and Supplementary Table 1). In comparison with the wild type, three gene mutants of C. glabrata showed significant reductions in biofilm formation, and the metabolic activities of these mutant biofilms were less than $70 \%$ of that of the wild type strain. The expressions of all three of these genes in C. glabrata during biofilm formation were detected as upregulated compared with those in planktonic cell conditions (Supplementary Figure 2). In particular, the expression levels of two genes in biofilm formation were more than two times higher than in planktonic cells. From a search of the Candida genome database, we found that one gene is a homolog of the SNARE protein family of $S$. cerevisiae. Since this gene showed the most drastic induction in the biofilm cells, we focused on this gene SYN8 (CAGL0H06325g) and characterized its deletion as the syn8 8 mutant. SYN8 in C. glabrata is a homolog of SYN8 in S. cerevisiae and of CR_03140C_A/SYN8 in C. albicans. In this study, the protein sequence of C. glabrata SYN8 was aligned with those of S. cerevisiae SYN8 and C. albicans SYN8, and the BLAST results showed that C. glabrata Syn8p shares $40 \%$ identity with S. cerevisiae Syn8p and 33\% identity with C. albicans Syn8p.

Next, the growth rate of the C. glabrata syn $8 \Delta$ strain was measured and compared with those of the wild type and a SYN8 reintegrated strain. The syn $8 \Delta$ mutant grew similarly to the wild type and reintegrated strains with a $24 \mathrm{~h}$ incubation in CSM medium, which was also used in the biofilm formation experiments (Supplementary Figure 3). After that, the biofilm formation of the syn $8 \Delta$ mutant was compared to those of the wild type strain and the reintegration SYN8 strain. On the non-siliconized plates made from polystyrene, the metabolic activity of the syn $8 \Delta$ mutant cells was significantly lower than those of the wild type strain and the SYN8 reintegrated strain when measured by XTT assay. In the siliconized plates (silicone coated polystyrene), the biofilm formation of the syn $8 \Delta$ mutant showed almost the same proportional reduction as that on the non-siliconized plates, while the reintegration SYN8 strain kept the same levels of biofilm formation compared to the wild type strain (Figure 2A). From these results, we used the non-siliconized plates in further experiments. To further compare the quantities of mature biofilm cells among the three strains, the biomass of the biofilms was measured. The dry weights of biofilms of the syn $8 \Delta$ mutant were almost half as much as those of the wild type strain, while

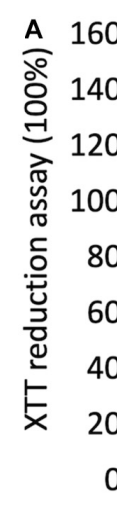

0 WT

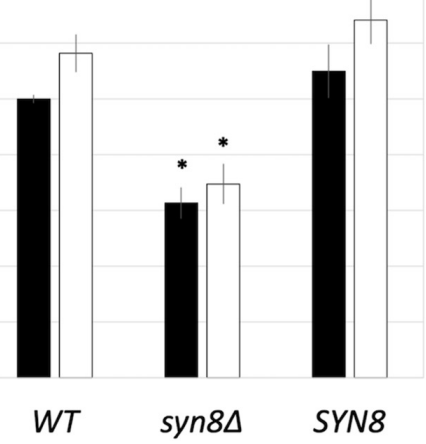

non-siliconized $\square$ siliconized

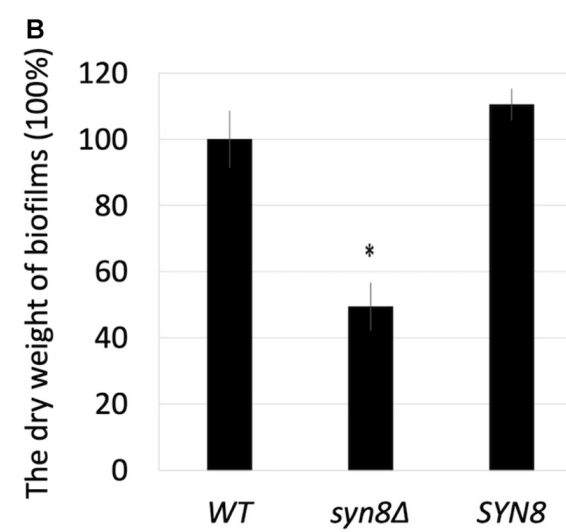

FIGURE 2 | Effect of siliconized plates on biofilm formation. (A) The metabolic activities of biofilms of the wild type strain, syn8 $\Delta$ mutant, and SYN8 reintegrated strain were detected in non-siliconized plates and siliconized plates, respectively. (B) Biofilms of the wild type strain, syn8 $\Delta$ mutant, and $S Y N 8$ reintegrated strain were respectively formed in 12-well plates, and the dry weight was measured. The reported values are the means $\pm S D$ of three independent experiments. ${ }^{*} p<0.05$ with Student's t-test. * vs. WT or SYN8. 
the reintegration SYN8 strain showed no decrease in biofilm biomass (Figure 2B).

The biofilm structures of these three strains on silicone sponges were observed by SEM. The SEM images showed that biofilms of the wild type strain extend widely with many cells, while few cells aggregated in the biofilm of the syn $8 \Delta$ mutant (Figure 3). The reintegration SYN8 strain recovered this phenotype of the mutant strain, indicating that the SYN8 gene is involved in the development of biofilms in C. glabrata. The reductions in metabolic activity, biomass, and biofilm development in the syn $8 \Delta$ mutant suggested that the SYN8 gene plays an important role in biofilm formation of C. glabrata.

Matrix analysis was performed to detect the carbohydrate and protein components in the matrix of biofilms. Table 4 shows the yield of total carbohydrate and protein separated from biofilm matrix formed by the wild type, the syn $8 \Delta$ mutant, and the reintegration strain. The total carbohydrate and protein in the biofilm matrix formed by the syn $8 \Delta$ mutant was much less than in the wild type and reintegration strains. However, when the amounts of carbohydrate and protein were normalized for the dry weight of the biofilm cells, the values showed no significant difference. This suggested that deletion of SYN8 had no effect on the proportion of biofilm matrix components in C. glabrata.

The first step in biofilm formation is cell adherence to the surface. The adherent activity of the syn $8 \Delta$ mutant during biofilm formation was also analyzed. After an initial $1.5 \mathrm{~h}$ of biofilm formation in siliconized plates, the non-adherent

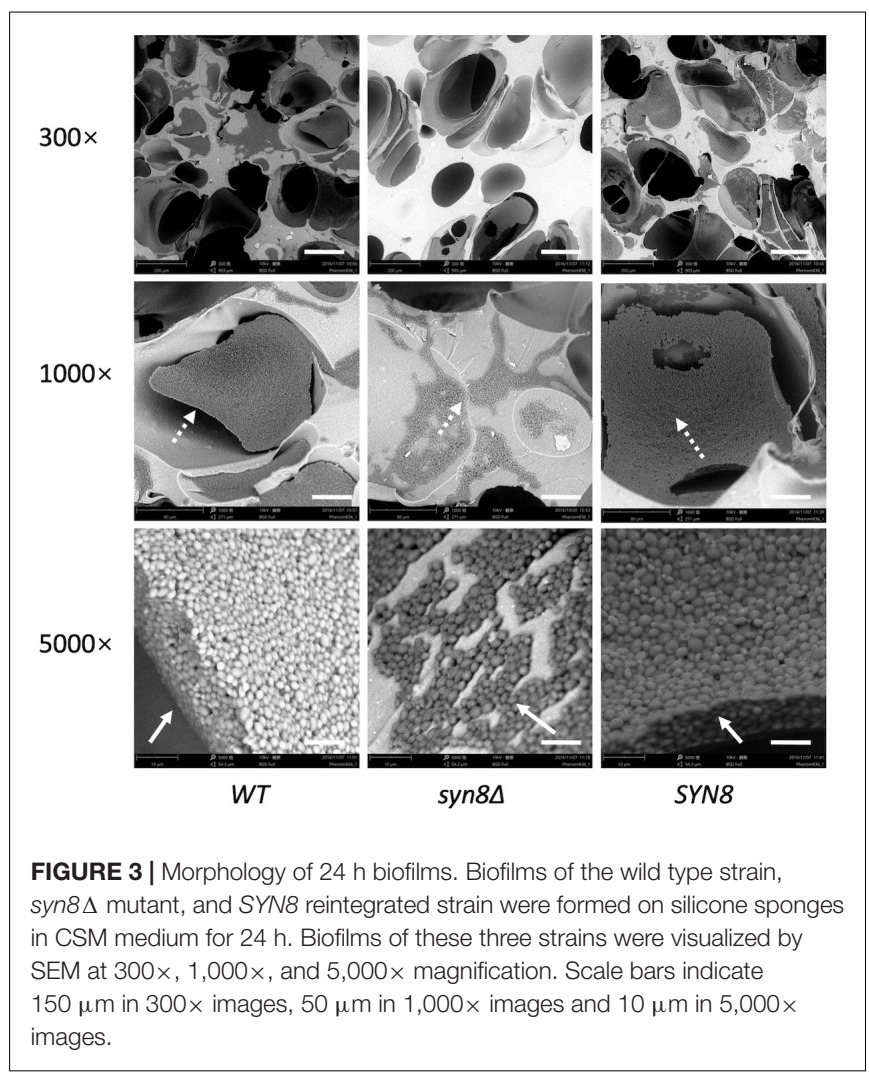

TABLE 4 | Biofilm matrix analysis for carbohydrate and protein components.

\begin{tabular}{lcccc}
\hline Strain & $\begin{array}{c}\text { Carbohydrate } \\
(\mu \mathrm{g} / \mathrm{mL})\end{array}$ & $\begin{array}{c}\text { Protein } \\
(\mu \mathrm{g} / \mathrm{mL})\end{array}$ & $\begin{array}{c}\text { Carbohydrate/ } \\
\text { biomass } \\
(\mu \mathrm{g} / \mathrm{mg})\end{array}$ & $\begin{array}{r}\text { Protein/ } \\
\text { biomass } \\
(\mu \mathrm{g} / \mathrm{mg})\end{array}$ \\
\hline$W T$ & $309.18 \pm 12.34$ & $3.36 \pm 0.49$ & $240.28 \pm 23.36$ & $2.66 \pm 0.74$ \\
SYn8 & $155.22 \pm 8.36$ & $1.72 \pm 0.32$ & $243.36 \pm 7.76$ & $2.725 \pm 0.74$ \\
SYN8 & $408.49 \pm 57.15$ & $4.34 \pm 0.21$ & $245.19 \pm 17.26$ & $2.65 \pm 0.69$
\end{tabular}

The reported values are the means $\pm S D$ of three independent experiments.

cells were washed away by PBS, and the metabolic activities of cells adherent to the surface of the plate bottom were measured by XTT assay. The syn $8 \Delta$ mutant showed around $70 \%$ metabolic activity compared with the wild type and reintegration strains (Figure 4A). When observing the adhesion step by SEM imaging, the results also showed that there were far fewer cells of the syn8 $\Delta$ mutant attached on the surface of the silicone compared with the wild type and reintegration strains (Figure 4B). Therefore, normal adhesion of biofilms seems to require Syn8p.

Because the syn8 mutant was observed to show poor adhesion, four adhesin genes, EPA1, EPA6, EPA10, and EPA22, were selected to investigate their transcriptional expression levels in the syn $8 \Delta$ mutant and the control strains under planktonic cell growth and biofilm formation conditions. There were no significant differences in the transcriptional expression levels of EPA1 and EPA6 genes under either condition. However, EPA10 and EPA22 showed decreased expression in the syn $8 \triangle$ mutant under both conditions compared with the wild type control (Figures 5A,B).

Although we found that the SYN8 gene contributes to biofilm formation and surface adhesion, it remained unclear whether this gene was related to stress resistance in biofilms of C. glabrata. Therefore, the growth of the syn $8 \Delta$ mutant in the presence of several antimicrobial reagents was detected by spot dilution assay. Compared to the wild type and SYN8 reintegrated strains, the syn $8 \Delta$ mutant showed significant defects in growth with SDS and hygromycin B. However, deletion of SYN8 seemed to show no change in susceptibility to calcofluor white and Congo red, which interfere with cell wall assembly (Figure 6).

Since these antimicrobial treatments show poor activity against biofilm cells when compared with planktonic cells, the MIC of hygromycin B to planktonic cells and the SMIC of hygromycin $\mathrm{B}$ to biofilm cells were measured. The $\mathrm{MIC}_{50}$ and $\mathrm{MIC}_{90}$ of planktonic cells of the syn $8 \Delta$ mutant were respectively 7.8125 and $62.5 \mu \mathrm{g} / \mathrm{mL}$ for hygromycin $\mathrm{B}$, values that were much lower than those of the wild type strain (62.5 and $250 \mu \mathrm{g} / \mathrm{mL})$ and SYN8 reintegrated strain (125 and $250 \mu \mathrm{g} / \mathrm{mL})$. The SMIC $_{50}$ and SMIC $_{90}$ of the syn $8 \Delta$ mutant biofilm cells were 125 and $1,000 \mu \mathrm{g} / \mathrm{mL}$, respectively, which were much higher than those of its own planktonic cells. However, the $\mathrm{SMIC}_{50}$ of the wild type strain and the integrated strain were 500 and $1,000 \mu \mathrm{g} / \mathrm{mL}$, respectively, and the $\mathrm{SMIC}_{90}$ of these strains was above $1,000 \mu \mathrm{g} / \mathrm{mL}$ (Table 5).

To synthesize mature proteins in cells normally, vacuolar functions such as vacuolar transport are necessary, and Syn8p is thought to be related to vacuolar function. To check the 


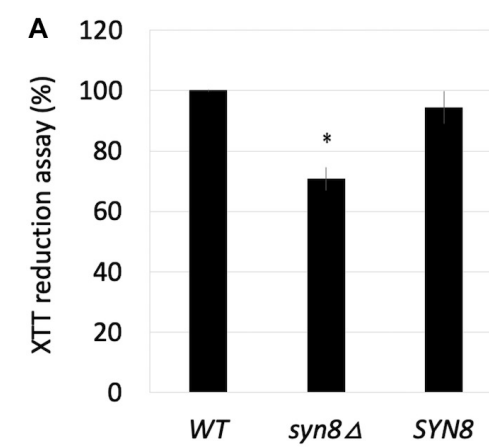

\section{B}

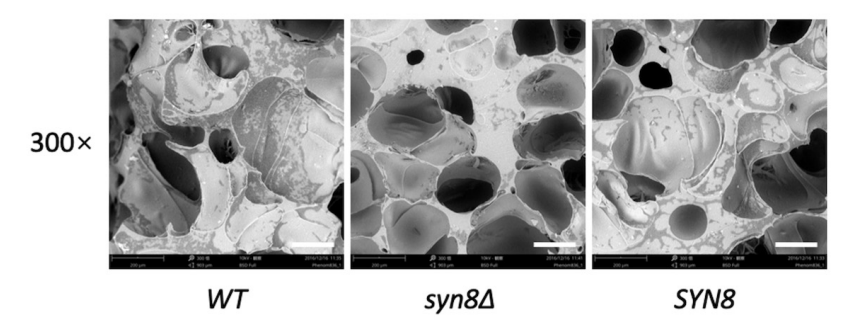

FIGURE 4 | Adhesion ability. (A) The metabolic activities of biofilms (1.5 h) of the wild type, syn8 $\Delta$ mutant, and SYN8 reintegrated strains were tested by XTT reduction assay. The reported values are the means $\pm S D$ of three independent experiments. ${ }^{*} p<0.05$ with Student's $t$-test, * vs. WT or SYN8. (B) The morphology of adhesion cells of the wild type, syn $8 \Delta$ mutant, and SYN8 reintegrated strains were visualized by SEM at $300 \times$ magnification. Scale bars indicate $150 \mu \mathrm{m}$ in $300 \times$ images.
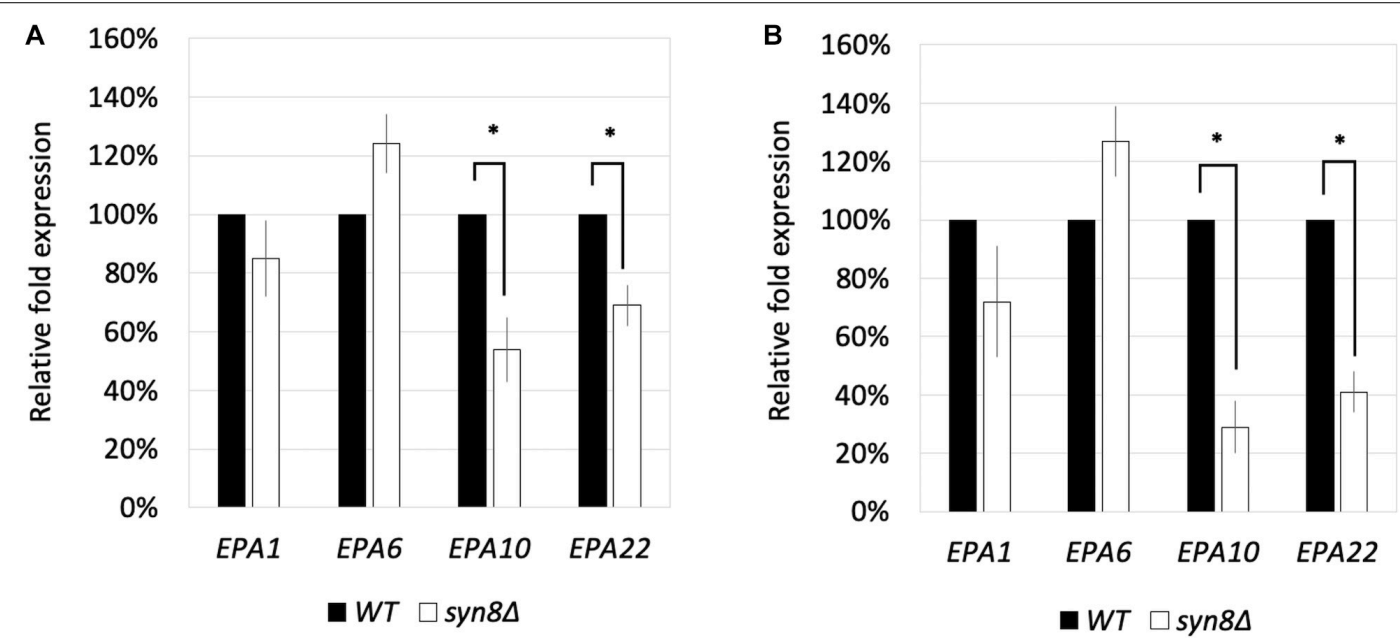

FIGURE $\mathbf{5}$ | The transcriptional expression levels of EPA1, EPA6, EPA10, and EPA22 in C. glabrata under planktonic cell growth conditions (A) and biofilm formation conditions (B). The gene expression values were normalized by comparison to the expression of a housekeeping gene, CgACT1. 100\% to the control group of wild type strain. Reported values indicate the means $\pm S D$ of at least three independent experiments. ${ }^{*} p<0.05$ with Student's $t$-test.

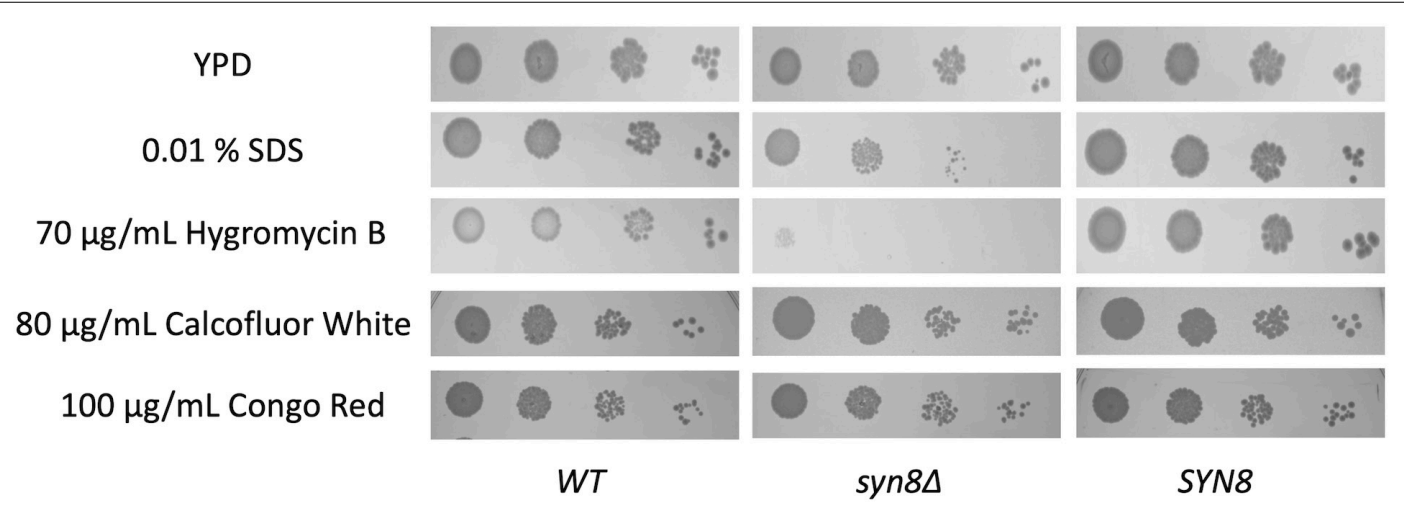

FIGURE 6 | Susceptibility to antifungals by spot-dilution assays. Overnight cultures were diluted in 10-fold serial dilutions and spotted onto YPD plates containing $0.01 \%$ SDS, $70 \mu \mathrm{g} / \mathrm{mL}$ hygromycin B, $80 \mu \mathrm{g} / \mathrm{mL}$ calcofluor white, and $100 \mu \mathrm{g} / \mathrm{mL}$ Congo red, respectively. 
TABLE 5 | MIC of planktonic cells and SMIC of biofilm cells to hygromycin B.

\begin{tabular}{|c|c|c|c|c|}
\hline \multirow[t]{2}{*}{ Strains } & \multicolumn{2}{|c|}{ Planktonic cells } & \multicolumn{2}{|c|}{ Biofilm cells } \\
\hline & $\begin{array}{c}\mathrm{MIC}_{50} \\
(\mu \mathrm{g} / \mathrm{mL})\end{array}$ & $\begin{array}{c}\mathrm{MIC}_{90} \\
(\mu \mathrm{g} / \mathrm{mL})\end{array}$ & $\begin{array}{l}\mathrm{SMIC}_{50} \\
(\mu \mathrm{g} / \mathrm{mL})\end{array}$ & $\begin{array}{l}\mathrm{SMIC}_{90} \\
(\mu \mathrm{g} / \mathrm{mL})\end{array}$ \\
\hline$W T$ & 62.5 & 250 & 500 & $>1,000$ \\
\hline syn8 8 & 7.8125 & 62.5 & 125 & 1,000 \\
\hline SYN8 & 125 & 250 & 1,000 & $>1,000$ \\
\hline
\end{tabular}

vacuolar function of the syn8 $\Delta$ mutant, it was assayed for growth under various types of ionic stress. The syn $8 \Delta$ mutant showed higher sensitivities to $\mathrm{ZnCl}_{2}, \mathrm{MnCl}_{2}$, and $\mathrm{NaCl}$ than the wild type strain (Supplementary Figure 4). In order to examine vacuole morphology, the fluorescent dye FM4-64 was used to stain vacuolar membranes and was viewed by CLSM. FM4-64 is a lipophilic styryl dye. Both the wild type and SYN8 reintegrated strains showed clear circle vacuolar membranes that were stained by FM4-64. But syn $8 \Delta$ mutant cells did not have a clear vacuole shape and looked to have large numbers of fragmented vacuoles (Figure 7 ). This result suggested that deletion of the C. glabrata SYN8 gene resulted in defective vacuole morphology.

\section{DISCUSSION}

Syn8 protein in S. cerevisiae has been identified as the SNARE protein syntaxin 8 , which plays a role in transport between the Golgi and prevacuolar compartments (PVC) (Lewis and Pelham, 2002). Previous findings have indicated that Syn8p may be a constituent of a SNARE complex with Vti1p, Pep12p, and Ykt6/Nyv1 proteins (Fischer Von Mollard and Stevens, 1999; Kweon et al., 2003).

Some studies on the relationship between biofilm formation and SNARE proteins in C. albicans and S. cerevisiae have been previously conducted. Pep12, which was mentioned above, has been reported to act as a t-snare protein and is classified into the Qa-/Syntaxin family (Lewis and Pelham, 2002). It has been reported to be involved in vacuolar transport and endocytosis in both S. cerevisiae and C. albicans (Kweon et al., 2003; Palanisamy et al., 2010). During biofilm formation of the C. albicans pep12A null mutant, there are notable defects in biofilm mass and biofilm integrity (Palanisamy et al., 2010). Another v-snare protein, Btn2, has also been demonstrated to play a role in biofilm formation in $S$. cerevisiae flor strains. Btn $2 \mathrm{p}$ facilitates the trafficking of specific proteins from the late endosome to the Golgi apparatus. Furthermore, the deletion of BTN2 affects biofilm formation due to alterations of the transcriptional level of the FLO11 gene, a critical gene for biofilm formation in S. cerevisiae (Espinazo-Romeu et al., 2008). Our study is the first to demonstrate a role for a SNARE protein in biofilm formation of C. glabrata.

Candida biofilms have been reported to exist frequently in the bodies of patients with silicone implant devices and are highly resistant to antifungal drugs (Pristov and Ghannoum, 2019). Medical devices made of silicone materials include urinary

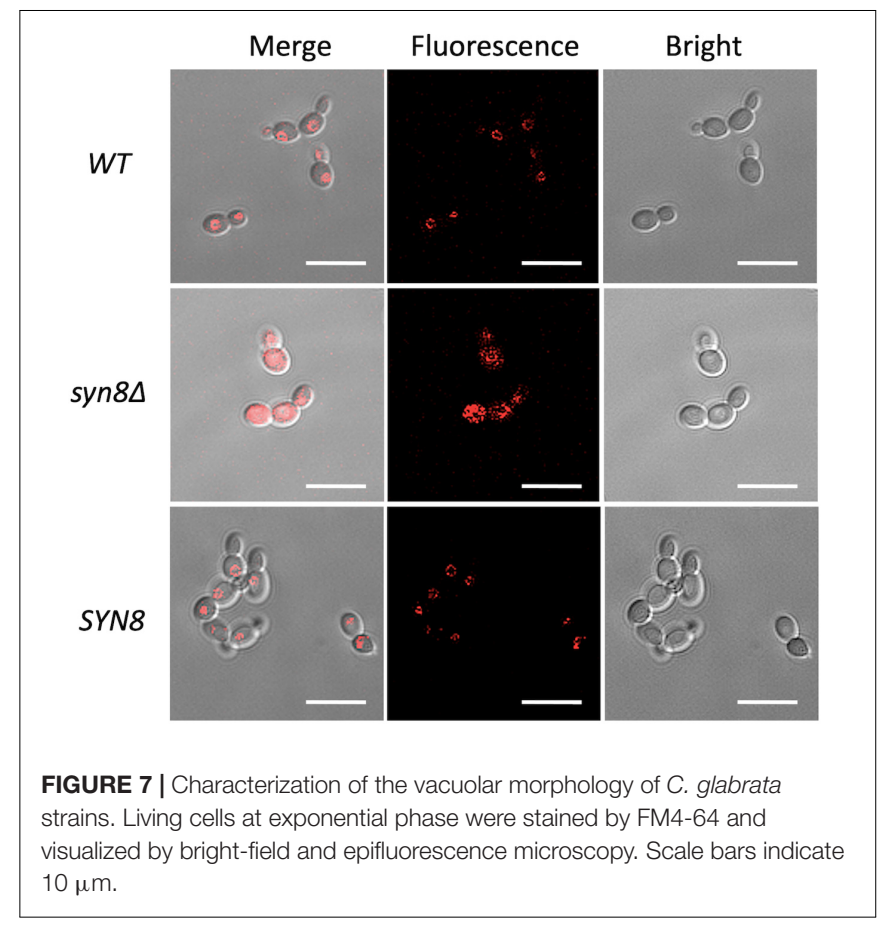

catheters, ventriculoperitoneal shunts, and voice prosthesis (Kojic and Darouiche, 2004). Therefore, not only commercial microtiter plates but also siliconized plates were used for biofilm formation of $C$. glabrata in this study. The syn $8 \Delta$ mutant decreased the metabolic activity of biofilms in both plate types. Furthermore, the syn $8 \Delta$ mutant seemed to be unable to form layers of dense biofilm structures and construct the same biofilm biomass as the wild type. Our in vitro model results strongly suggest that SYN8 is required for proper C. glabrata biofilm formation. Further work will be need to elucidate the function of this gene in biofilm model in vivo.

Mature biofilm structures consist of yeast cell layers and extracellular matrix, which mainly includes carbohydrates and proteins (Silva et al., 2009). The protein and carbohydrate amounts were also reduced in the syn $8 \Delta$ mutant, although the absence of the SYN8 gene did not influence the ratio of extracellular matrix components to biofilm biomass. Moreover, deletion of the SYN8 gene in C. glabrata resulted in a decrease in the adhesion to the surface of the silicone plates. Since adhesion and production of extracellular matrix are significant steps to from biofilms of C. glabrata, these results suggested that SYN8 might affect not only the adhesion ability in the early stage of biofilm formation, but also the extracellular matrix production in the late stage of biofilm formation.

The EPA gene family is a major group of adhesin-like glycosylphosphatidylinositol-cell-wall proteins (GPI-CWPs) of C. glabrata. Epa1p plays a critical role in adherence in C. glabrata. Epa6p has also been shown to play an important role during biofilm formation although it is not involved in adherence to the surface of plates (Iraqui et al., 2005). EPA1, EPA6, and EPA10 share the same homolog in S. cerevisiae, FLO1, while the EPA22 homolog in S. cerevisiae is FLO10. The Flo protein family in 
S. cerevisiae has been reported to mediate yeast flocculation, adherence, and biofilm formation (Verstrepen and Klis, 2006). In order to clarify the relationship between EPA gene expression and SYN8 disruption in C. glabrata, the transcriptional expressions of EPA1, EPA6, EPA10, and EPA22 during planktonic cell growth and biofilm formation were analyzed in the syn $8 \Delta$ mutant. Since the expression levels of both EPA10 and EPA 22 in the syn8D mutant were much lower in biofilm formation than planktonic cell growth, these proteins may be needed for adhesion activity in biofilms of C. glabrata. Further research into these two EPA genes will be required to determine their relationship with the SYN8 gene.

In addition, testing the resistance to several stressors demonstrated that the deletion of SYN8 led to increased susceptibility to hygromycin B especially, not only in planktonic cells but also in biofilm cells. Hygromycin B inhibits translocation of mRNA and tRNA on the ribosome and interferes with decoding fidelity. It is widely used in veterinary medicine and in selection for cell culture (Borovinskaya et al., 2008). Based on previous research on $S$. cerevisiae, many mutants such as VPS1, VPS34, VPS45, and VPS54 with vacuole trafficking or functional defects show hypersensitivity to hygromycin B (Banuelos et al., 2010; Smaczynska-de Rooij et al., 2010). Moreover, these VPS mutants have decreased growth in the presence of various ions, similar with the syn8 $\Delta$ mutant in this study. This could be because vacuoles act as storage vessels for a wide variety of ions, responding to ionic shock and promoting intracellular ion homeostasis. For instance, $\mathrm{Na}^{+}$and $\mathrm{K}^{+}$are major cations in the cytosol, while they are minor components in the vacuolar pools (Rodríguez-Navarro, 2000). Excessive concentrations of $\mathrm{Mg}^{2+}$ and $\mathrm{Zn}^{2+}$ can become harmful to cells (Simm et al., 2007). In addition, our CLSM images showed that the vacuole morphologies of the syn $8 \Delta$ mutant were abnormal when compared to the wild type strain. In $S$. cerevisiae, fragmented vacuoles are observed in the VPS54 null mutant (Raymond et al., 1992). From our findings, the syn $8 \Delta$ mutant of C. glabrata appeared to have defective vacuolar morphology and the detail study on the role of SYN8 gene in the vacuolar function is expected in future research.

Vps proteins of $S$. cerevisiae have been reported to be required for the assembly of SNARE complexes during fusion between the trans-Golgi network and PVC. For example, some Vps proteins, together with the vacuolar SNARE proteins, function in the fusion of multiple transport intermediates with the vacuole (Sato et al., 2000). Some C. albicans Vps proteins, like Vps1p, have also been reported to be involved in biofilm formation

\section{REFERENCES}

Banuelos, M. G., Moreno, D. E., Olson, D. K., Nguyen, Q., Ricarte, F., AguileraSandoval, C. R., et al. (2010). Genomic analysis of severe hypersensitivity to hygromycin B reveals linkage to vacuolar defects and new vacuolar gene functions in Saccharomyces cerevisiae. Curr. Genet. 56, 121-137.

Bat’ová, M., Džugasová, V., Borecká, S., Goffa, E., Oblasová, Z., and Šubík, J. (2009). Molecular and phenotypic analysis of mutations causing anionic phospholipid deficiency in closely related yeast species. Folia. Microbiol. 54, 30-36. doi: 10.1007/s12223-009-0005-x
(Bernardo et al., 2008). Therefore, it has been proposed that SNARE proteins and Vps proteins may act together on the secretory pathway, which plays a role in Candida virulence, such as biofilm formation (Rollenhagen et al., 2020).

\section{DATA AVAILABILITY STATEMENT}

The raw data supporting the conclusions of this article will be made available by the authors, without undue reservation.

\section{AUTHOR CONTRIBUTIONS}

$\mathrm{XC}$ and SK conceived the study and wrote the manuscript. XC performed the experiments. XC and SI collected and analyzed the data. TK and HC gave support. All authors contributed to the article and approved the submitted version.

\section{ACKNOWLEDGMENTS}

We thank the Open Research Facilities for Life Science and Technology in the Tokyo Institute of Technology for technical support and equipment and Tokyo Institute of Technology for internal funds to us.

\section{SUPPLEMENTARY MATERIAL}

The Supplementary Material for this article can be found online at: https://www.frontiersin.org/articles/10.3389/fcell.2021. 607188/full\#supplementary-material

Supplementary Figure 1 | Biofilm formation by 101 gene mutants of $C$. glabrata by XTT assay. $100 \%$ to the reference strain.

Supplementary Figure 2 | The transcriptional expressions of three C. glabrata genes in mature $(24 \mathrm{~h})$ biofilm cells compared with planktonic cells.

Supplementary Figure 3 | The growth rates of the wild type strain, syn8 $\Delta$ mutant and SYN8 reintegrated strain.

Supplementary Figure 4 | Susceptibility to antifungals by spot-dilution assays. Overnight cultures were diluted in 10-fold serial dilutions and spotted onto YPD plates containing $4 \mathrm{mM} \mathrm{ZnCl}_{2}, 10 \mathrm{mM} \mathrm{MnCl}_{2}, 1 \mathrm{M} \mathrm{KCl}$, and $1 \mathrm{M} \mathrm{NaCl}$, respectively.

Supplementary Table 1 | Biofilms of mutants in percentages relative to the reference strain (100\%).

Bernardo, S. M., Khalique, Z., Kot, J., Jones, J. K., and Lee, S. A. (2008) Candida albicans VPS1 contributes to protease secretion, filamentation, and biofilm formation. Fungal Genet. Biol. 45, 861-877. doi: 10.1016/j.fgb.2008. 01.001

Borovinskaya, M. A., Shoji, S., Fredrick, K., and Cate, J. H. D. (2008). Structural basis for hygromycin B inhibition of protein biosynthesis. RNA 14, 1590-1599. doi: 10.1261/rna.1076908

Brunke, S., and Hube, B. (2013). Two unlike cousins: Candida albicans and C. glabrata infection strategies. Cell Microbiol. 15, 701-708. doi: 10.1111/cmi. 12091 
Cavalheiro, M., Costa, C., Silva-Dias, A., Miranda, I. M., Wang, C., Pais, P., et al. (2018). A transcriptomics approach to unveiling the mechanisms of in vitro evolution towards fluconazole resistance of a Candida glabrata clinical isolate. Antimicrob. Agents Chemother. 63:e00995-18. doi: 10.112 8/AAC

Chen, X., Zhang, R., Takada, A., Iwatani, S., Oka, C., Kitamoto, T., et al. (2017). The role of Bgl2p in the transition to filamentous cells during biofilm formation by Candida albicans. Mycoses 60, 96-103. doi: 10.1111/myc. 12554

Culakova, H., Dzugasova, V., Perzelova, J., Gbelska, Y., and Subik, J. (2013). Mutation of the CgPDR16 gene attenuates azole tolerance and biofilm production in pathogenic Candida glabrata. Yeast 30, 403-414. doi: 10.1002/ yea. 2978

de Groot, P. W., Kraneveld, E. A., Yin, Q. Y., Dekker, H. L., Gross, U., Crielaard, W., et al. (2008). The cell wall of the human pathogen Candida glabrata: differential incorporation of novel adhesin-like wall proteins. Eukaryot. Cell 7, 1951-1964. doi: 10.1128/EC.00284-08

Douglas, L. J. (2003). Candida biofilms and their role in infection. Trends Microbiol. 11, 30-36. doi: 10.1016/s0966-842x(02)00002-1

Dubois, M., Gilles, K., Hamilton, J. K., Rebers, P. A., and Smith, F. (1956). Colorimetric method for determination of sugars and related substances. Anal. Chem. 28, 350-356. doi: 10.1021/ac60111a017

Eix, E. F., and Nett, J. E. (2020). How biofilm growth affects Candida-host interactions. Front. Microbiol. 11:1437. doi: 10.3389/fmicb.2020.01437

Espinazo-Romeu, M., Cantoral, J. M., Matallana, E., and Aranda, A. (2008). Btn2p is involved in ethanol tolerance and biofilm formation in flor yeast. FEMS Yeast Res. 8, 1127-1136. doi: 10.1111/j.1567-1364.2008.00397.x

Fischer Von Mollard, G., and Stevens, T. H. (1999). The Saccharomyces cerevisiae V-SNARE Vtilp is required for multiple membrane transport pathways to the vacuole. Mol. Biol. Cell 10, 1719-1732. doi: 10.1091/mbc.10.6.1719

García-Sánchez, S., Aubert, S., Iraqui, I., Janbon, G., Ghigo, J. M., and d’Enfert, C. (2004). Candida albicans biofilms: a developmental state associated with specific and stable gene expression patterns. Eukaryot. Cell 3, 536-545. doi: 10.1128/EC.3.2.536-545.2004

Iraqui, I., Garcia-Sanchez, S., Aubert, S., Dromer, F., Ghigo, J. M., d'Enfert, C., et al. (2005). The Yaklp kinase controls expression of adhesins and biofilm formation in Candida glabrata in a Sir4p-dependent pathway. Mol. Microbiol. 55, 1259-1271. doi: 10.1111/j.1365-2958.2004.04475.x

Kojic, E. M., and Darouiche, R. O. (2004). Candida infections of medical devices. Clin. Microbiol. Rev. 17, 255-267. doi: 10.1128/cmr.17.2.255-267.2004

Koszul, R., Malpertuy, A., Frangeul, L., Bouchier, C., Wincker, P., Thierry, A., et al. (2003). The complete mitochondrial genome sequence of the pathogenic yeast Candida (Torulopsis) glabrata. FEBS Lett. 16, 39-48. doi: 10.1016/s00145793(02)03749-3

Kweon, Y., Rothe, A., Conibear, E., and Stevens, T. H. (2003). Ykt6p is a multifunctional yeast R-SNARE that is required for multiple membrane transport pathways to the vacuole. Mol. Biol. Cell 14, 1868-1881. doi: 10.1091/ mbc.E02-10

Lewis, M. J., and Pelham, H. R. (2002). A new yeast endosomal SNARE related to mammalian syntaxin 8. Traffic 3, 922-929. doi: 10.1034/j.1600-0854.2002. 31207.x

Nobile, C. J., Fox, E. P., Nett, J. E., Sorrells, T. R., Mitrovich, Q. M., Hernday, A. D., et al. (2012). A recently evolved transcriptional network controls biofilm development in Candida albicans. Cell 148, 126-138. doi: 10.1016/j.cell.2011. 10.048

Palanisamy, S. K., Ramirez, M. A., Lorenz, M., and Lee, S. A. (2010). Candida albicans PEP12 is required for biofilm integrity and in vivo virulence. Eukaryot. Cell 9, 266-277. doi: 10.1128/EC.00295-09

Pfaffl, M. W. (2001). A new mathematical model for relative quantification in real-time RT-PCR. Nucleic Acids Res. 29:e45.

Pristov, K. E., and Ghannoum, M. A. (2019). Resistance of Candida to azoles and echinocandins worldwide. Clin. Microbiol. Infect. 25, 792-798. doi: 10.1016/j. cmi.2019.03.028

Ramage, G., Mowat, E., Jones, B., Williams, C., and Lopez-Ribot, J. (2009). Our current understanding of fungal biofilms fungal biofilms gordon
Ramage et Al. Crit. Rev. Microbiol. 35, 340-355. doi: 10.3109/1040841090324 1436

Ramage, G., Vande Walle, K., Wickes, B. L., and López-Ribot, J. L. (2001). Standardized method for in vitro antifungal susceptibility testing of Candida albicans biofilms. Antimicrob. Agents Chemother. 45, 2475-2479. doi: 10.1128/ AAC.45.9.2475-2479.2001

Raymond, C. K., Howald-Stevenson, I., Vater, C. A., and Stevens, T. H. (1992). Morphological classification of the yeast vacuolar protein sorting mutants: evidence for a prevacuolar compartment in class E Vps mutants. Mol. Biol. Cell 3, 1389-1402. doi: 10.1091/mbc.3.12.1389

Riera, M., Mogensen, E., d'Enfert, C., and Janbon, G. (2012). New regulators of biofilm development in Candida glabrata. Res Microbiol. 163, 297-307. doi: 10.1016/j.resmic.2012.02.005

Rodrigues, C. F., Silva, S., and Henriques, M. (2014). Candida glabrata: a review of its features and resistance. Eur. J. Clin. Microbiol. Infect. Dis. 33, 673-688. doi: 10.1007/s10096-013-2009-3

Rodríguez-Navarro, A. (2000). Potassium transport in fungi and plants. Biochim. Biophys. Acta 1469, 1-30. doi: 10.1016/s0304-4157(99)00013-1

Rodríguez-Tudela, J. L., Barchiesi, F., Bille, J., Chryssanthou, E., CuencaEstrella, M., Denning, D., et al. (2003). Method for the determination of minimum inhibitory concentration (MIC) by broth dilution of fermentative yeasts. Clin. Microbiol. Infect. 9, 1-8. doi: 10.1046/j.1469-0691.2003. 00789.x

Rollenhagen, C., Mamtani, S., Ma, D., Dixit, R., Eszterhas, S., and Lee, S. A. (2020). The role of secretory pathways in Candida albicans pathogenesis. J. Fungi 6:26. doi: 10.3390/jof6010026

Santos, R., Cavalheiro, M., Costa, C., Takahashi-Nakaguchi, A., Okamoto, M., Chibana, H., et al. (2020). Screening the Drug:H+ antiporter family for a role in biofilm formation in Candida glabrata. Front. Cell Infect. Microbiol. 10:29. doi: $10.3389 /$ fcimb.2020.00029

Santos, R., Costa, C., Mil-Homens, D., Romão, D., de Carvalho, C. C., Pais, P., et al. (2017). The multidrug resistance transporters CgTpol_1 and CgTpo1_2 play a role in virulence and biofilm formation in the human pathogen Candida glabrata. Cell Microbiol. 19:e12686. doi: 10.1111/cmi.12686

Sato, T. K., Rehling, P., Peterson, M. R., and Emr, S. D. (2000). Class C Vps protein complex regulates vacuolar SNARE pairing and is required for vesicle docking/fusion. Mol. Cell. 6, 661-671. doi: 10.1016/s1097-2765(00)00 064-2

Silva, S., Henriques, M., Martins, A., Oliveira, R., Williams, D., and Azeredo, J. (2009). Biofilms of non-Candida albicans Candida species: quantification, structure and matrix composition. Med. Mycol. 47, 681-689. doi: 10.3109/ 13693780802549594

Simm, C., Lahner, B., Salt, D., LeFurgey, A., Ingram, P., Yandell, B., et al. (2007). Saccharomyces cerevisiae vacuole in zinc storage and intracellular zinc distribution. Eukaryot. Cell 6, 1166-1177. doi: 10.1128/EC.000 77-07

Smaczynska-de Rooij, Allwood, E. G., Aghamohammadzadeh, S., Hettema, E. H., Goldberg, M. W., and Ayscough, K. R. (2010). A role for the dynamin-like protein Vps1 during endocytosis in yeast. J. Cell Sci. 123, 3496-3506. doi: $10.1242 /$ jcs.070508

Taff, H. T., Nett, J. E., Zarnowski, R., Ross, K. M., Sanchez, H., Cain, M. T., et al. (2012). A Candida biofilm-induced pathway for matrix glucan delivery: implications for drug resistance. PLoS Pathog. 8:e1002848. doi: 10.1371/journal. ppat. 1002848

Ueno, K., Matsumoto, Y., Uno, J., Sasamoto, K., Sekimizu, K., Kinjo, Y., et al. (2011). Intestinal resident yeast Candida glabrata requires Cyb2p-mediated lactate assimilation to adapt in mouse intestine. PLoS One 6:e24759. doi: 10. 1371/journal.pone.0024759

Ueno, K., Uno, J., Nakayama, H., Sasamoto, K., Mikami, Y., and Chibana, H. (2007). Development of a highly efficient gene targeting system induced by transient repression of YKU80 expression in Candida glabrata. Eukaryot. Cell 6, 1239-1247. doi: 10.1128/EC.00414-06

Vandenbosch, D., De Canck, E., Dhondt, I., Rigole, P., Nelis, H. J., and Coenye, T. (2013). Genomewide screening for genes involved in biofilm formation 
and miconazole susceptibility in Saccharomyces cerevisiae. FEMS Yeast Res. 13, 720-730. doi: 10.1111/1567-1364.12071

Verstrepen, K. J., and Klis, F. M. (2006). Flocculation, adhesion and biofilm formation in yeasts. Mol. Microbiol. 60, 5-15. doi: 10.1111/j.1365-2958.2006. 05072.x

Vida, T. A., and Emr, S. D. (1995). A new vital stain for visualizing vacuolar membrane dynamics and endocytosis in yeast. J. Cell Biol. 128, 779-792. doi: $10.1083 /$ jcb.128.5.779

Widiasih Widiyanto, T., Chen, X., Iwatani, S., Chibana, H., and Kajiwara, S. (2019). Role of major facilitator superfamily transporter Qdr2p in biofilm formation by Candida glabrata. Mycoses 62, 1154-1163. doi: 10.1111/myc.13005
Conflict of Interest: The authors declare that the research was conducted in the absence of any commercial or financial relationships that could be construed as a potential conflict of interest.

Copyright (c) 2021 Chen, Iwatani, Kitamoto, Chibana and Kajiwara. This is an open-access article distributed under the terms of the Creative Commons Attribution License (CC BY). The use, distribution or reproduction in other forums is permitted, provided the original author(s) and the copyright owner(s) are credited and that the original publication in this journal is cited, in accordance with accepted academic practice. No use, distribution or reproduction is permitted which does not comply with these terms. 